\section{Plagiarism charge casts shadow on peer review}

\section{- Referee accused of abusing privilege - Author plans appeal against NIH ruling}

\section{Washington}

A SERIOUS abuse of the peer review system has been alleged by an investigating committee of the National Institutes of Health involving a paper published in the journal Science. A short announcement in Science last week revealed that an NIH investigation found that a paper published in 1987 had plagiarized information published two months earlier in the Proceedings of the National Academy of Sciences (PNAS).

"The wanton abuse of the peer review system with the clear intention of personal aggrandizement, attacks the very fabric of the scientific enterprise", says the report of the NIH investigation. "In the view of this panel, the charge of theft - plagiarism - is at least as serious a misconduct in science as outright fabrication of experimental data,..."

The author charged with plagiarism is C. David Bridges, then at Baylor College of Medicine in Houston, Texas and now at Purdue University. His paper (Science 236, 1678; 1987) is considered by NIH to have used information from a manuscript by Paul S. Bernstein, Wing C. Law and Robert R. Rando, all of Harvard Medical School (PNAS 84, 1849; 1987).

$\mathrm{NIH}$ has recommended that Bridges be debarred from receiving federal funding for a period to be determined, be excluded from service on any Department of Health and Human Services' peer review commitee for ten years and that NIH support for his current work should be terminated.

Bridges denies all the charges laid against him and intends to appeal NIH's findings. No blame was attached by NIH to Bridges' co-author and senior technician, Richard A. Alvarez.

The paper by Rando and colleagues reported the activity of an enzyme, isomerase, that completes the visual cycle that regenerates the visual pigment, rhodopsin, in the vertebrate eye.

The dispute began in July 1986 when Bridges was sent a copy of the Rando manuscript to review for PNAS. Eight weeks later Bridges returned the paper, excusing himself from reviewing it on the grounds that he was already engaged in similar work.

In November, Bridges submitted to Nature a paper that also claimed to demonstrate a retinol isomerase. But Nature declined publication. Bridges then revised the paper and submitted it to Science, which accepted it for publication in April 1987, just over three weeks after the
Rando paper was published in PNAS.

At about the same time, Rando became aware of Bridges' work, through an abstract prepared for the annual meeting of the Association for Research in Vision and Opthalmology (ARVO). He saw its similarity to the research he described in his $P N A S$ paper and was able to find out that Bridges had been sent the paper for review, and that Bridges had a paper in press at Science.

The dispute could have ended at this point, for Rando did not accuse Bridges of plagiarism, and Bridges claimed (as he still does) that his own experiments began months before he saw Rando's manuscript. All Rando asked was that Bridges acknowledge his research. At the annual ARVO meeting, Rando met Bridges and they agreed on modifications of the Science paper, then in galley proof, that would have clearly acknowledged the priority of Rando's PNAS paper.

But according to the NIH report, Bridges "unilaterally modified the agreedupon changes" and "attempted to claim priority for the discovery in news releases (instigated and authorized by him) which were devoid of any mention of the the Rando publication". Only then did Rando talk to Alvarez, Bridges' co-author, and hear that Bridges had not begun experiments on the isomerase until August 1986 after Bridges had received Rando's manuscript to review. When Rando passed this news to Baylor College, it was decided to set up a committee of investigation. The committee's report, issued in May 1988 . triggered a full NIH investigation.

The NIH panel was at first frustrated in its efforts to tackle the key issue of when Bridges began his experiments. It criticized the quality of Science's review process, finding the paper contained "internal inconsistencies, incomplete data, and misinformation". The panel was "dismayed by the absence of unequivocal documentation" - all the research records were facsimiles drawn from computer records, and the dates on them could easily have been altered.

But the panel found that a key piece of evidence remained: the shipment records for the radioactive retinol needed to conduct the experiments. The NIH panel found that the records "coincide with a chronology of experimentation beginning in August", after the Rando paper had arrived. Insufficent retinol was available to conduct the experiments earlier, in the panel's opinion.

\section{LEP in line for August advance}

\section{Washington}

A Low-energy positron beam successfully circumnavigated the ring of magnets constituting the Large Electron-Positron Collider (LEP), the new machine at CERN (European Laboratory for Particle Physics) in Geneva, Switzerland. At $20 \mathrm{GeV}$, the positrons were far below the design energy of $100 \mathrm{GeV}$, but this first test demonstrated that the magnets were all correctly aligned and that the high vacuum system for the ring was sound.

A similar test of the counter-rotating electron ring was scheduled for Tuesday of this week, and first physics experiments are planned for early August. David Lindley

The panel's judgement was clinched by an examination of the evolution of the research. When questioned by the committee, Rando was able to give "considered and empirically sound answers" for his choice of experimental conditions that included a low ethanol reaction mixture. But Bridges "did not provide convincing scientific justifications for the changes from his established methods", and "attributed to luck his asking for "minimal ethanol'...".

The panel concluded that the successful procedure "was revealed to Bridges in its entirety through some intuitive leap (a rarity in experimental science)...or was plagiarized from the Rando manuscript". This logic and other inconsistencies in Bridges' protocol led the NIH panel to declare Bridges had commited plagiarism.

Could Science have done more to to deal with the Bridges'case before publication? Rando says that he does not "have any complaints at all" about Science's handling of the paper. He wrote to Science before the paper was published to say he had entered into an agreement with Bridges on changes to the paper. But he notes, "I did not say I suspected plagiarism"

Daniel Koshland, editor of Science. says that on the basis of the information the journal had at the time, "it would not have been fair to hold up the paper". As manuscript editors at Nature know well, complaints about incomplete citation of earlier work are common but generally of no great substance.

The case also brings up the muchdebated question of who owns data gained in research paid for by federal funds. The NIH committee felt that it was incumbent upon Bridges to produce original data and was not convinced by claims that the data had been stolen or discarded. The investigatory panel stressed that it was a mistake for the Baylor College committee to think that the laboratory notebooks were Bridges' personal property.

Alun Anderson 